To appear in The Anthropocene Review. Author final version, July 2016.

\title{
Viewing the technosphere in an interplanetary light
}

\author{
Bronislaw Szerszynski (Lancaster University, UK) \\ bron@lancaster.ac.uk
}

\begin{abstract}
In this paper I argue that discussion about the 'technosphere' as an emergent new Earth system needs to be situated within wider reflection about how technospheres might arise on other worlds. Engaging with astrobiological speculation about 'exo-technospheres' can help us to understand whether technospheres are likely, what their preconditions might be, and whether they endure. Engaging with science fiction can help us to avoid observer biases that encourage linear assumptions about the preconditions and emergence of technospheres. Exploring earlier major transitions in Earth's evolution can shed light on the shifting distribution of metabolic and reproductive powers between the human and technological parts of the contemporary technosphere. The long-term evolution of technical objects also suggests that they have shown a tendency to pass through their own major transitions in their relation to animality. Such reflection can shed new light on the nature and likely future development of the Earth's technosphere.
\end{abstract}

\section{Keywords}

technosphere, Anthropocene, astrobiology, macroevolution, history of technology, science fiction

In an important series of papers, Peter Haff (2010; 2014a; 2014b; 2014c) has proposed a new way of looking at technology, one which treats it, along with human beings and their institutions, as parts of an emergent component of the Earth system, the 'technosphere', which he suggests is a crucial defining feature of the proposed new geological epoch the 'Anthropocene'. For Haff, the technosphere includes all large-scale interconnected technological systems such as those involved in energy, transportation and agriculture, the devices, human beings and institutions directly and indirectly involved in their operation, and the built environment that sustains and supports all of these (Haff, 2014a: 127). He argues that the technosphere constitutes a 'newly emerged Earth system' comparable to the other dynamic Earth systems or 'paradigms' on which it supervenes such as the lithosphere, hydrosphere and biosphere (ibid.: 126). Like these, it is global, appropriates resources including mass and energy, and exhibits a degree of systemic autonomy by generating its own internal laws (Haff, 2014d: 7). These laws or 'rules' constrain the behaviour and possibilities for action of its constituent parts, whether technological or human. Humans, for example, can only interact with elements at the same systemic level, are under pressure to contribute to the efficiency and viability of the whole, and are increasingly unable to opt out of the technosphere or significantly alter its tendency to entrain more and more of the Earth's resources in its operation (Haff, 2014a). In this paper I will argue that our understanding of the technosphere and the Anthropocene can be further enriched by reflecting on the possibility of 'exo-technospheres' - technospheres that might develop or have developed elsewhere in the universe and independently of human society.

Although the Earth's technosphere includes elements other than technological artefacts, and anyway as a whole displays emergent properties that cannot be reduced to those of its constituent parts, nevertheless it is clear that technologies are central in shaping its character and dynamic. As a starting definition, by 'technology' or 'technical object' - including tools, machines, devices, and so on - I will mean 
an entity (usually but not always material, solid, non-living and deliberately made or altered) that is used by another entity in order to realise an intention, goal or function. Technologies can be said to have two faces or dimensions (Sigaut, 1985: 437): working is more 'internal' and concerns the way that a technology harnesses physical effects or principles, such as those involved in electric motors; 'function' (later I will also use the term 'teleonomy') concerns the 'external' role that the tool or machine performs in a wider action sequence or social or technical system.

Later in this paper I will say more about the different kinds of technical object and the relations between them. Here, however, I will not provide strict definitions - either for a technology as a specific kind of entity, or for the technosphere as a specific kind of planetary system, and this for a number of reasons. Firstly, it is central to my argument that technology, rather like biological life, is undergoing secular change, and that it is only once we understand that process of change that we will be able to adequately grasp the fundamental character of technology. Secondly, as long as our definition and understanding of technology is confined solely to its relation to the human species (or other imagined intelligent animals), and that of the technosphere to the specific history of the Earth as a planet, we will only see them, as it were, in a dim and narrow-spectrum illumination. While the 'speculative planetology' provided by science fiction can help to challenge deep assumptions about the ways that exo-technospheres might emerge, I will also suggest - perhaps counterintuitively - that by attending more closely to the details of the historical development of the Earth and its component entities, and of the changing relationship between the human animal and its technological artefacts, we can start to view them in a more revealing, interplanetary light.

\section{Exo-technospheres}

Technology is no longer an Earthbound phenomenon, because of the thousands of tonnes of satellites, space probes and inoperative 'space junk' in Earth orbit or on and around other planetary bodies, which together constitute an assemblage with various emergent properties (Gorman, 2014; 2015). However, this kind of space technology is an extension of the Earth's technosphere - and indeed increasingly essential to its efficient operation. What about technospheres that might have arisen completely independently of human society? Within the astrobiological community there has been extensive debate about the possibility, probability and likely development of extra-terrestrial technological civilisations. Much astrobiological deliberation has focused on the so-called Fermi paradox and Drake Equation. The Fermi paradox, as formulated by Enrico Fermi in 1950, consists in the apparent contradiction between the high probability of the existence of extra-terrestrial civilisations as estimated by science, and the lack of any empirical evidence of their existence, despite the best efforts of SETI (Search for Extra-Terrestrial Intelligence). Frank Drake formulated his eponymous equation for the likely number of detectable extraterrestrial civilisations in 1961. In its traditional form, it is as follows:

$$
\mathrm{N}=\mathrm{R} * \times f_{\mathrm{p}} \times n_{e} \times f_{1} \times f_{1} \times f_{\mathrm{i}} \times f_{\mathrm{c}} \times \mathrm{L}
$$

in which $\mathrm{N}$, the predicted number of detectable civilisations, is the product of $\mathrm{R}_{*}$ (the rate of star formation), $f_{\mathrm{p}}$ (the average number of planets around stars), $n_{e}$ (the fraction of these planets that can support life), $f_{i}$ (the fraction of these where life actually emerges), $f_{i}$ (the fraction of these where intelligence emerges), $f_{\mathrm{t}}$ (the fraction of these where a technological society capable of transmitting radio signals emerges), and $L$ (the lifetime of such technological societies). Other writers have broadened the definition of $\mathrm{N}$ away from the emphasis on detectability towards the more general category of technological civilisations, and thus the emergence of technospheres; for example, Frank and Sullivan (2014) refer to 'Species with Energy-Intensive Technology' (SWEIT). Many of the variables in the Drake Equation remain almost impossible to constrain, but estimations have generally had the effect of intensifying the puzzle of the Fermi paradox. Why do we not see any evidence of exo-technospheres?

In order to resolve the Fermi paradox, Robin Hanson (1998) hypothesised the existence of a 'Great Filter' that must be operating at some stage in planetary development, preventing a greater number of otherwise suitable planets from currently hosting technological civilisations. This filter may be one that the 
Earth has already successfully passed, which implies that developing a technosphere is very difficult for planets to achieve; or it may be one that the Earth has still to confront, which implies that a technosphere is very difficult to maintain (see also Bostrom, 2008). Whereas earlier commentators (e.g. Sagan and Newman, 1983) hypothesised that many technospheres might be destroyed by internal military conflict, more recent speculation focuses on the difficulties of avoiding environmental catastrophe (Frank and Sullivan, 2014). Another line of thinking is that perhaps it just takes time for the universe to become sufficiently hospitable for the widespread emergence of life and intelligence (Ćirković, 2006), and that in order to develop technospheres perhaps planets have to pass through not one but a number of filters, any one of which it might fail for completely contingent reasons (Watson, 2008).

Such astrobiological reflection already suggests many important supplementary questions to ask about technospheres. For example, are technospheres a likely outcome of planetary development? What are the preconditions for their emergence? Once they are established, are there particular trajectories of development that they are likely to follow - and do these imply short or long lifespans? The answers we give to all of these questions will have significant implications for how we understand 'our' own technosphere, and the Earth's geological prospects.

\section{Speculative planetology}

As Milan Ćirković argues, if and when we ever encounter extra-terrestrial life forms or technological artefacts, they may confound our existing categories and we may struggle to recognise them (Ćirković, 2012, chapter 8). However, within astrobiological reflection there is a constant temptation to accord the particular path of planetary evolution undergone by the Earth with a privileged status. For example, although Frank Drake says that the intention behind his eponymous equation was merely to stimulate debate, with its implicit left-to-right chronological structure it nevertheless tends to reinforce the idea that advanced technology is the final, albeit not inevitable step in an orderly sequence of star formation, planet formation, the emergence of life, the emergence of intelligence, society and civilisation, then finally that of science and technology. It should also be remarked that the very competing definitions of $\mathrm{N}$ (that which we value and are looking for elsewhere in the cosmos) - 'intelligent observers', 'technological societies', 'energy-intensive civilisations', even 'civilisation' itself - are far from ideologically neutral categories, even on the Earth, let alone in space. Carter (1983) and Watson (2008) both argue that the strictly necessary steps for intelligent observerhood are probably very few, which implies that all the other evolutionary steps that have de facto shaped the character of the Earth, of human beings and of the Earth's technosphere (for example the emergence of placental mammals) were probably not necessary for the arising of intelligence or a technosphere. But nevertheless, in their series of 'critical steps' of geological timespans, Carter and Watson still reproduce the idea of a linear path - however pared down and unlikely to be successfully traversed - along which a planet must pass if a technosphere is to emerge.

We need to be more imaginative about the possible paths that could be taken in the selforganisation of matter in planetary evolution: we need to cultivate 'speculative planetology'. Convergence on high intelligence may only be a local effect of conditions that happened to obtain on the Earth (Lineweaver, 2008), and there may be diverse evolutionary strategies with their own positive feedback loops that favour the optimisation of very different capacities in lineages of organisms arising in different environments (Yafremava et al., 2013). We cannot say a priori that a technosphere can only emerge in a society of intelligent, language-using animals. But in order to stretch our imagination about the possible origins of technospheres, astrobiological theorisation needs to be enriched by wider sources such as science fiction.

The Polish science fiction writer and philosopher Stanisław Lem wrote a series of deeply philosophical novels exploring the moment of first contact with alien life, including most famously Solaris (1970). His late novel Fiasko, published in English in 1987, presents us with two haunting scenarios for planetary evolution. The first is a vision of organic forms arising without life. It takes place on Saturn's moon Titan, where astronaut Parvis travels through an extraordinary crystalline terrain. On lifeless Titan, 'where eternal death still reigned' (Lem, 1987: 30) and natural selection had thereby not operated as a 
filter, matter's self-organising powers had operated without constraint, and produced extensive, uncanny landscapes resembling boneyards and forests.

The second is the possible scenario of technology arising without individuated animals. This occurs in the later part of the novel, which describes an expedition to the fifth planet (dubbed 'Quinta') of the star Zeta Harpyiae, from which have been detected signals suggesting an extra-terrestrial technological civilisation. The Quintans seem strangely reluctant to respond to initially friendly human contact, and their planet is surrounded by odd technological artefacts, many of which seem to serve no purpose. The human expedition's attempts to make contact are guided by an assumption that sophisticated technological systems can only emerge in animal societies, and result in a disastrous series of misunderstandings. Mark Tempe, an astronaut who has a personal obsession with actually 'seeing' the Quintans, is chosen to land and make contact. In the final chapter he lands on the planet, but what seem at first sight to be recognisable technological features such as spaceports and roads become more difficult to render at close contact. A massive, extensive web of tendrils, more organic than artefactual in appearance, is suspended from masts across the landscape; a hangar-like structure on closer examination looks more like a giant inflated corpse in the form of an inside-out copy of a captured Earth ship; nothing that look remotely like terminals suggest how the Quintans interface with their technology; mounds looking like primitive huts, burial mounds, tortoise shells or mushroom fruiting bodies are assumed to be dwellings, but contain no metazoan inhabitants but simply tubular structures. Tempe finally concludes that the 'Quintans' are not individuated animals, and perhaps never have been, but are something more like fungi or slime moulds.

Lem's speculative planetologies should provoke us to at least attempt to drop some of our Earthbound observer biases in imagining the arising of forms in planetary environments, and to ask new kinds of question about the nature of the Earth's own technosphere. For example: to what extent has our technosphere been conditioned by its particular evolutionary path, and especially by the fact that metazoic life - life individuated into large, mobile multi-cellular animals - has played a crucial role in its emergence? Does anything about its trajectory suggest that exo-technospheres might arise through very different patterns of planetary development?

\section{Major transitions}

Perhaps paradoxically, attending to the detailed specifics of the transitions undergone by the Earth in its ongoing self-organisation can help expand our thinking about the technosphere. Crucial here are the debates inspired by the work of John Maynard-Smith and Eörs Szathmáry on major transitions in biological evolution (Maynard Smith and Szathmáry, 1995; Szathmáry and Maynard Smith, 1995). Maynard-Smith and Szathmáry argued that evolution has undergone highly significant moments of transformation in the very units of evolution and the mechanisms by which evolution proceeds. The (much debated) list of eight major transitions that they proposed are those from replicating molecules to populations of molecules in compartments; from unlinked replicators to chromosomes; from RNA as gene and enzyme to DNA and protein (i.e. the emergence of the genetic code); from prokaryotes to eukaryotes; from asexual clones to sexual populations; from protists (early eukaryotes) to animals, plants and fungi (cell differentiation); from solitary individuals to colonies with non-reproductive castes; and from primate societies to language-using human societies (Maynard Smith and Szathmáry, 1995; Szathmáry and Maynard Smith, 1995).

Incorporating the technosphere fully within this litany of 'major transitions' would involve expanding the definition of the latter away from its emphasis on the biological organism. Nevertheless, even without such an expansion it is possible, with care, to use the analysis of earlier transitions to shed light on the technosphere. Here I want to focus on one feature shared by many major transitions: the combination of formerly distinct individuals into stable new evolutionary and ecological individuals. The clearest examples of these are the enclosure of replicating molecules within a membrane, the fusion of unrelated prokaryotes into the eukaryotic cell, and the organisation and specialisation of genetically identical cells into multi-cellular plants, fungi and animals.

Can we regard the emergence of the technosphere as a major transition to a new kind of stable association, even though it is neither a functional and evolutionary 'individual' itself, nor composed of stable individual cyborgs, but a continuously shifting coupling of organic and inorganic matter? To help us 
here, we need to move to a more dynamic understanding of hierarchical structure in complex systems. Haff (2014a) argues that the entities that make up any system can be described as organised into three strata Stratum I, Stratum II and Stratum III - each of which contains entities which are progressively larger and at higher organisational levels than the previous stratum. In Haff's terminology, an evolutionary individual is composed of a number of Stratum I units such as cells, but is itself a Stratum II entity that associates with other Stratum II entities (whether belonging to the same genetic lineage or not) in Stratum III structures such as societies, symbioses and ecosystems. But as Carl Simpson (2011) and others argue, hierarchies in living systems are not static but themselves evolve. In such 'transitions in individuality', evolutionary fitness passes from the Stratum II entities to the Stratum III structures, which become a new kind of evolutionary individual.

Crucially, for each such transition in individuality to become permanent, mechanisms must emerge which prevent the new, higher-level individuals reverting to their constituent parts. In Haff's language, the new individuals must find new methods of enforcing his 'six rules', especially the 'rule of performance' which ensures that each constituent unit supports the functioning of the whole. For example, in the eukaryotic cell, the energy-giving mitochondria, once free-living eukaryotes, are now completely dependent on the wider cell architecture for their reproduction. Similarly, in multicellular animals a division of labour between germ and soma cells prevents any cell from defecting back to solitary living by ensuring that no cell possesses both the capacity for independent metabolism and that of reproduction (Michod and Roze, 1997; Simpson, 2012).

Against this background, the balance of mutual dependency concerning both metabolism and reproduction in the evolving association between humans and technology seems to be shifting in interesting ways. Firstly, the individual components of the technosphere - both humans and technologies - are increasingly dependent on their membership of the technosphere. Haff (2014a; 2014c) has drawn attention to how humans find it increasingly hard to leave the technosphere; but technologies too are becoming more tied in, both metabolically (for example in terms of their energy needs) and reproductively (in complex networks of manufacturing and innovation). In this sense, the evolution of the technosphere seems to follow the pattern of earlier macroevolutionary transitions on the Earth. However, secondly, there is also a shifting distribution of powers between the human and technical components of the technosphere, and here the pattern is rather different. If indeed technologies are moving towards 'general intelligence' and self-replication, then it rather appears that, unlike for example the prokaryotes which became the mitochondria within the eukaryotic cell, technologies are being granted the powers of reproduction and independent teleonomic purpose rather than having them taken away. Placed in the light of evolutionary biology, contemporary concerns about the technological singularity and impending human obsolescence (Bostrom, 2013; Shanahan, 2015) start to feel like the latest twist in a story that is almost as old as the Earth itself.

\section{The technosphere and the metazoa}

Let us focus more closely on the changing relationship between technologies and animals within the technosphere. I want to argue that the evolution of the Earth's technosphere has exhibited a shifting relationship with what I call 'metazoic being' - the mode of existence of multicellular animals - and that this provides further clues to the character of technospheres as planetary phenomena. The emergence around 600,000 years ago of multicellular animals was hugely significant for the Earth. Central to this significance were three interrelated novel features of the animal's mode of existence: a large, moving, eating, articulated body; mortal, sexually reproducing individuals organised into distinct species; and a sensory, phenomenological world organised into space and time (Szerszynski, 2016). While the metazoa constituted and still constitute a small proportion of the Earth's biomass, their arrival was crucial in shifting the Earth from its biogeographically uniform Proterozoic state into the familiar Phanerozoic world - Gaia as we know it - made up of diverse complex ecosystems, high levels of diversification, biomass, energy-use and nutrient recycling and fast evolution, all driven by the presence of large, feeding multi-tissue organisms (Butterfield, 2007; 2011). 
Just as the Phanerozoic biosphere was arguably brought into being by animals in general, the Earth's technosphere was brought into being by a particular kind of animal. It is clearly no accident that this was an animal in possession of a large cognitive capacity and one whose development of language and culture had already liberated it from a purely instinctive relationship with its environment. But the evolution of the technological entities within the technosphere can, I suggest, give us clues about the more general relationship between technospheres and metazoic being. Here I will use terminological distinctions developed by two theorists of technology, Gilbert Simondon (1958) and Brian Arthur (2009). Thus I will speak of what Simondon calls the technical 'elements' (Arthur's 'components') that make up technologies; technical 'individuals' (Arthur's 'technology singular') that appears as discrete, unified entities devised to fulfil a specific purpose; and Simondon's technological 'ensembles' such as factories and laboratories, and Arthur's broader technological 'domains' such as mining and weaving, in which discrete technical individuals are assembled in interacting networks.

In the early stages of the evolution of technology it was the association of tools with metazoa such as humans that gave them certain metazoan characteristics. Firstly, although technical objects like living things exhibit teleonomy - a function, purpose or final cause - in their case this is borrowed from the living things that make and use them (Nöth, 2009). Arthur (2009: 50-1) defines technology as 'a phenomenon ... or ... collection of phenomena captured and put to use', and (on the Earth at least) it is ultimately the use to the animal organism that makes it a technology. Secondly, the need for tools and machines to be put to use by humans also gave them a characteristic size and number that was commensurate with the metazoic body. This is still the case even with many contemporary technologies: on Earth, unlike on Quinta, computer systems typically have at least some interfaces such as screens and keyboards designed for interaction with the human body. Thirdly, early human technologies like those of other tool-using animals largely served to extend the individual powers of the body as arranged across its various organs and limbs arms, fists, fingers, eyes, ears (McLuhan, 1964). The first human tools - such as a hard stone augmenting the power of the fist to pound or drive in stakes - worked by capturing and putting to use phenomena and material properties that could be directly experienced by the senses (Arthur, 2009: 171), but also in ways that were tied to the organismically divided powers of the animal body, in what Bernard Stiegler (2015) calls a 'general organology'. So the 'clades' or lineages of early technologies - spears, bowls, needles and so on - were determined by the bodily form of the animals that made and wielded them, and many continue to be so.

However, as human tools and their use became more sophisticated there was a tendency for them to develop further metazoa-like features due to what might be called their own internal needs independently of their need to interact with animals. Firstly, tools were made more effective through the combination of multiple 'tissues' with different material properties and functions. Secondly, as the technosphere evolved, this simple combination of different materials was supplemented with something closer to the hierarchical structure of multi-cellular being. As Arthur (2009: 33) argues, contemporary technologies are typically assembled from components, each of which supports the function of the whole and is also a technology in its own right. Thirdly, with the emergence of more complex and motorised 'technical individuals' such as engines and machines, the tendency is towards fewer, larger entities closer in form to the metazoan body rather than to its constituent limbs and organs, entities which themselves undergo evolution into more unified, 'concretised' syntheses of form and function (Simondon, 1958).

The rise of technical individuals also introduced more metazoa-like ecological relations to the emerging technosphere. Firstly, technical individuals are typically associated with a particular artificial 'associated milieu' that is generated around them in order to support their functioning, for example the tracks, shunting yards, goods sheds and stations associated with the railway engine - with some, 'hypertelic' individuals more dependent on this milieu than others (Simondon, 1958). As Simondon clarifies, technical individuals such as motors and mechanisms usually need to be relatively isolated from each other, even when working together in an ensemble such as a factory. Secondly, the ontogenesis (coming into being) and persistence of technologies is also dependent on niches that can be occupied, embedded in wider 'domains' such as dyeing and manufacturing. This combination of milieus, ensembles, niches and domains creates what Simondon calls a 'technogeographical' world, mimicking the spatially complex biogeographical world of the Phanerozoic aeon. Thirdly, an increasingly integrated technosphere also 
exhibits the tendency of the Phanerozoic Earth system to cascades of 'creative destruction', as niches are created, reoccupied and destroyed in continuous, self-organised criticality (Arthur, 2009: 178).

So we can see that there are many ways in which the increased integration of the technosphere has had the tendency of strengthening the metazoa-like features of technical objects in both their internal structure and their outward relations. However, there are also ways in which the Earth's technosphere shows tendencies that depart from the metazoic, animal form, and it is these to which I now turn. Firstly, despite its lifelike nature as a dynamic, combinatorial 'metabolic chemistry' of interacting, evolving entities exhibiting formal causation (Arthur, 2009: 205), technology has always had features that has made it very different from the animal and indeed other living kingdoms. The evolution of new technologies often involve the combination of radically different technical lineages, and thus resemble more the bacterial than the animal exchange of genetic information (Basalla, 1988). More generally, the evolution of technology exhibits little of the material (and code) continuity that tie all living things with each other through their last universal common ancestor (LUCA); and whereas organisms can only evolve in incremental steps from existing components, and in ways that ensure that all generations are viable, technology is not bound by these limits (Arthur, 2009: 188).

Secondly, the technosphere seems to be moving away from a structure of relatively isolated technical individuals to more fungiform integrated technical systems that are opaque to the comprehension of the human animal. As Haff (2014a) argued, the autonomisation of the technosphere is related to the necessity of any dynamic system to constrain interaction between its different levels. Haff's 'rule of reciprocity' means that systemic imperatives ensure that Stratum I entities such as individual cells in the human body or components within a television can generally only directly interact with other Stratum I entities. Similarly, humans as Stratum II entities within the technosphere 'can deal directly only with other Stratum II systems ... such as automobiles or cell phones' (Haff, 2014a: 133).

But whereas technology was once a Stratum II phenomenon, commensurate with the human body, it is increasingly recursive, with no characteristic scale: modern technologies are technologies all the way down to the smallest transistor and all the way up through ensembles and domains to the global technosphere itself (Arthur, 2009: 38, 42). As Arthur puts it, in the contemporary world 'the "representative technology" is not a machine with fixed function but a system, a network or metabolism of "thingsexecuting-things"', and such systems are developing the ability to learn and configure themselves (Arthur, 2009: 206, 207). Rather like Lem's astronaut Mark Tempe faced by the mysterious mounds on Quinta, when we 'lift the lid' on modern technology we find not so much individual technical 'individuals' commensurate with the limbs or whole body of the human person, but the webs and tendrils of a rhizomatic network.

\section{Conclusion}

In this paper I have argued that discussion about the technosphere and the Earth's possible current geological transition needs to be expanded; it is only by situating the Earth's particular trajectory of development within a wider 'phase space' of possible such trajectories, both real and imagined, that we can hope fully to understand what is occurring on the Earth. Engaging with astrobiological deliberation about 'exo-technospheres', technospheres on other worlds, can help us to understand whether technospheres are likely phenomena, what their preconditions might be, and (not least) whether they are likely to be relatively short-lived phenomena and if so why. However, I also suggested that engaging with science fiction can help us to avoid observer biases that encourage linear assumptions about the preconditions of technospheres - particularly the assumption that technology must be preceded by the emergence of intelligent animals. I explored how looking at earlier major transitions in the selforganisation of the Earth system can help shed light on the emergence and development of the technosphere, especially regarding the shifting distribution of metabolic and reproductive powers between its human and technological constituent units. I then suggested that the evolution of technical objects suggests that they have shown a tendency to pass through their own major transitions, in which the dynamics governing their ontogenesis and phylogenesis have shifted: from borrowed, exogenous animal characteristics, to their own endogenous animality, and finally to a non-animal form. 
Such reflection might help us at least start to reflect on which features of the Earth's technosphere are the result of the Earth's particular contingent path of development, and which might be intrinsic to technospheres in general. Amongst other things, this could provide new ideas about how the Earth's technosphere might develop in the long-term future. For Haff, the unintelligibility and autonomy of the technosphere from the point of view of the individual human animal is merely an instance of the 'rule of reciprocity' that constrains interaction between strata in every self-organising system. But if we regard this unintelligibility and autonomy not as a timeless rule but as an evolutionary tendency, perhaps the technosphere is gradually escaping not just its animal makers, but its erstwhile shadowing of animal form. Many philosophers have speculated that this might indeed be the final destiny of technospheres, and thought too (e.g. Lyotard, 1991: 8-23).

There are a number of possible implications of the above analysis, which I can here only lay out for future consideration. One is a story of divergence: that it is the initial tying to the animal (or some other form of organised organic matter) that makes technospheres, for a while, commensurate and capable of contact. In Lem's Fiasco, fictional astrobiologists use this idea to solve or at least diminish the force of the Fermi paradox: in the evolution of technospheres, they suggest, perhaps there is a temporal 'window of contact' of centuries or at most millennia between the emergence of a technosphere and it becoming postanimal, and thus beyond the point of mutual intelligibility (Lem, 1987: 92). The opposite possibility is a story of convergence: that technospheres start from very different and mutually unintelligible places, conditioned by the particular forms of organised matter from which they emerge, but then escape this conditioning and converge on an autonomous logic, or perhaps a few such logics. Some support for this idea is suggested by what is happening to Earth technology in space, where physical distance from humans necessitates technological autonomy (Gorman, 2015: 44). In between these two relatively simple possibilities, of course, lies a plethora of far more complex possible dynamics.

Understanding the nature of the Earth's technosphere, the way it supervenes on the Earth's earlier 'spheres' and phases of development, and its possible future history, are all key to understanding the real significance of the changes in the Earth system being discussed under the heading of the Anthropocene. Clarifying the relationship between the apparent runaway, expansive logic of the Earth's technosphere and the shifting balance of powers of its human and technological components could tell us much about whether ecological contradiction is an inherent danger for all technospheres, or only for those emerging from particular pathways of planetary evolution. But we can only even frame such questions, let alone start to answer them, if we view the technosphere in an interplanetary light.

\section{References}

Arthur B. (2009) The Nature of Technology: What It Is and How It Evolves, New York: Free Press.

Basalla G. (1988) The Evolution of Technology, Cambridge: Cambridge University Press.

Bostrom N. (2008) Where are they? Why I hope the search for extraterrestrial life finds nothing. MIT Technology Review May/June: 72-77.

Bostrom N. (2013) Superintelligence: Paths, Dangers, Strategies, Oxford: Oxford University Press.

Butterfield NJ. (2007) Macroevolution and macroecology through deep time. Palaeontology 50: 41-55.

Butterfield NJ. (2011) Animals and the invention of the Phanerozoic Earth system. Trends in Ecology \& Evolution 26: 81-87.

Carter B. (1983) The anthropic principle and its implications for biological evolution. Philosophical Transactions of the Royal Society of London A 310: 347-363.

Ćirković MM. (2006) Too early? on the apparent conflict of astrobiology and cosmology. Biology and Philosophy 21: 369-379.

Ćirković MM. (2012) The Astrobiological Landscape: Philosophical Foundations of the Study of Cosmic Life, Cambridge: Cambridge University Press.

Frank A and Sullivan W. (2014) Sustainability and the astrobiological perspective: framing human futures in a planetary context. Anthropocene 5: 32-41.

Gorman A. (2014) The Anthropocene in the solar system. Journal of Contemporary Archaeology 1: 73-132. 
Gorman A. (2015) Robot avatars: the material culture of human activity in earth orbit. In: O'Leary LB and Capelotti JP (eds) Archaeology and Heritage of the Human Movement into Space. Cham: Springer International Publishing, 29-47.

Haff PK. (2010) Hillslopes, rivers, plows, and trucks: mass transport on Earth's surface by natural and technological processes. Earth Surface Processes and Landforms 35: 1157-1166.

Haff PK. (2014a) Humans and technology in the Anthropocene: six rules. The Anthropocene Review 1: 126136.

Haff PK. (2014b) Maximum Entropy Production by Technology. In: Dewar RC, Lineweaver CH, Niven RK, et al. (eds) Beyond the Second Law: Entropy Production and Non-Equilibrium Systems. New York: Springer, 397-414.

Haff PK. (2014c) Technology as a geological phenomenon: implications for human well-being. Geological Society, London, Special Publications 395: 301-309.

Haff PK. (2014d) Technology as a geological phenomenon: implications for human well-being. In: Waters $\mathrm{CN}$, Zalasiewicz JA, Williams M, et al. (eds) A stratigraphical basis for the Anthropocene? . London: Geological Society of London.

Hanson R. (1998) The Great Filter - Are We Almost Past It? Available at: http://mason.gmu.edu/ rhanson/greatfilter.html.

Lem S. (1970) Solaris, New York, : Walker.

Lem S. (1987) Fiasco, London: Andre Deutsch.

Lineweaver $\mathrm{CH}$. (2008) Paleontological tests: human-like intelligence is not a convergent feature of evolution. In: Seckbach J and Walsh M (eds) From Fossils to Astrobiology: Records of Life on Earth and Search for Extraterrestrial Biosignatures. New York: Springer, 353-368.

Lyotard J-F. (1991) The Inhuman: Reflections on Time, Cambridge: Polity Press.

Maynard Smith J and Szathmáry E. (1995) The Major Transitions in Evolution, Oxford: Oxford University Press.

McLuhan M. (1964) Understanding Media: The Extensions of Man, London: Routledge and Kegan Paul.

Michod RE and Roze D. (1997) Transitions in individuality. Proceedings of the Royal Society B 264: 853-857.

Nöth W. (2009) On the instrumentality and semiotic agency of signs, tools, and intelligent machines. Cybernetics and Human Knowing 16: 11-36.

Sagan C and Newman WI. (1983) The solipsist approach to extraterrestrial intelligence. Quarterly Journal of the Royal Astronomical Society 24: 113-121.

Shanahan M. (2015) The Technological Singularity, Cambridge, MA: MIT Press.

Sigaut F. (1985) More (and enough) on technology! History and Technology 2: 115-132.

Simondon G. (1958) Du mode d'existence des objets techniques, Paris: Aubier.

Simpson C. (2011) How many levels are there? How insights from evolutionary transitions in individuality help measure the hierarchical complexity of life. In: Calcott B and Sterelny K (eds) The Major Transitions in Evolution Revisited. Cambridge, MA: MIT Press, 200-225.

Simpson C. (2012) The evolutionary history of division of labour. Proceedings of the Royal Society of London B: Biological Sciences 279: 116-121.

Stiegler B. (2015) Symbolic Misery, Volume 2: The Catastrophe of the Sensible, Oxford: Polity.

Szathmáry E and Maynard Smith J. (1995) The major evolutionary transitions. Nature 374: 227-232.

Szerszynski B. (2016) Out of the Metazoic? Animals as a transitional form in planetary evolution. In: Tønnessen M, Rattasepp S and Amstrong Oma K (eds) Thinking about Animals in the Age of the Anthropocene. Lexington, MA: Lexington Books, 163-179.

Watson AJ. (2008) Implications of an anthropic model of evolution for emergence of complex life and intelligence. Astrobiology 8: 175-185.

Yafremava LS, Wielgos M, Thomas S, et al. (2013) A general framework of persistence strategies for biological systems helps explain domains of life. Frontiers in Genetics 4. 